\title{
Natural infection in anopheline species and its implications for autochthonous malaria in the Atlantic forest in Brazil
}

\author{
Ana Maria RC Duarte ${ }^{1 *}$, Diego M Pereira ${ }^{1}$, Marcia B de Paula ${ }^{2}$, Aristides Fernandes ${ }^{2}$, Paulo R Urbinatti ${ }^{2}$, \\ Andressa F Ribeiro ${ }^{2}$, Maria Helena SH Mello ${ }^{3}$, Marco O Matos $\mathrm{Jr}^{3}$, Luís F Mucci ${ }^{4}$, Lícia N Fernandes ${ }^{5}$, \\ Delsio Natal ${ }^{2}$ and Rosely S Malafronte ${ }^{5,6}$
}

\begin{abstract}
Background: A descriptive study was carried out in an area of the Atlantic Forest with autochthonous malaria in the Parelheiros subdistrict on the periphery of the municipality of São Paulo to identify anopheline fauna and anophelines naturally infected with Plasmodium as well as to discuss their role in this peculiar epidemiological context.

Methods: Entomological captures were made from May 2009 to April 2011 using Shannon traps and automatic CDC traps in four areas chosen for their different patterns of human presence and incidences of malaria (anthropic zone 1, anthropic zone 2, transition zone and sylvatic zone). Natural Plasmodium infection was detected by nested PCR based on amplification of the 18S rRNA gene.

Results: In total, 6,073 anophelines were collected from May 2009 to April 2011, and six species were identified in the four zones. Anopheles cruzii was the predominant species in the three environments but was more abundant in the sylvatic zone.

Anopheles (Kerteszia) cruzii specimens from the anthropic and sylvatic zones were positive for $P$. vivax and $P$. malariae. An. (Ker.) bellator, An. (Nys.) triannulatus, An. (Nys.) strodei, An. (Nys.) lutzi and An. (Ano) maculipes were found in small numbers. Of these, An. (Nys.) triannulatus and An. (Nys.) lutzi, which were collected in the anthropic zone, were naturally infected with P. vivax while An. (Nys.) triannulatus from the anthropic zones and An. (Nys.) strodei from the transition zone were positive for P. malariae.

Conclusion: These results confirm that Anopheles (Kerteszia) cruzii plays an important role as a major Plasmodium vector. However, the finding of other naturally infected species may indicate that secondary vectors are also involved in the transmission of malaria in the study areas. These findings can be expected to help in the implementation of new measures to control autochthonous malaria in areas of the Atlantic Forest.
\end{abstract}

Keywords: Autochthonous malaria, Plasmodium, Anophelines, Natural infection, Atlantic forest

\footnotetext{
*Correspondence: amrcd2@gmail.com

${ }^{1}$ Biochemistry and Molecular Biology Laboratory, Superintendency for the Control of Endemic Diseases (SUCEN), Rua Paula Souza 166, São Paulo 01027-000, Brazil

Full list of author information is available at the end of the article
} 


\section{Background}

The peculiar epidemiological situation regarding malaria in the Atlantic Forest in the southern and southeastern regions of Brazil is characterized by atypical cases involving asymptomatic or oligosymptomatic individuals, most of whom are infected with Plasmodium vivax and live in forested areas; one main mosquito vector, Anopheles (Kerteszia) cruzii, whose larval phase develops in bromeliad axils; and the presence of wild monkeys that could act as reservoirs [1-8].

The finding outside the Amazon region of individuals with antibodies against sporozoite and asexual forms of $P$. vivax and $P$. malariae and of a few human cases with low malaria parasitemias reinforces the hypothesis, supported by several authors [1-3], that asymptomatic individuals may act as a source of transmission in the extraAmazon region. However, the etiological origin of these cases remains unclear and the presence of monkeys naturally infected with $P$. brasilianum and $P$. simium in these areas suggests that wild reservoirs of Plasmodium may be involved in the malaria cycle [4-6].

Even though the ecological aspects of $A n$. (Ker.) cruzii are well known [9], little information about natural malaria infection in this vector is available. During the ' $40 \mathrm{~s}$ there were reports, based on microscopic observations, of natural infection in specimens of the Kerteszia subgenus collected in southeastern Brazil [10]. More recently, $A n$ (Ker.) cruzii specimens tested by ELISA were found to be infected with the classic and VK247 variants of $P$. vivax [11].

The objective of this research was to describe the epidemiological context in the region where these anophelines are found, an area of Atlantic Forest with autochthonous malaria transmission located in the Parelheiros subdistrict on the periphery of the municipality of São Paulo. In addition, as the region has the largest number of notified cases of the disease in the Atlantic Forest in the state of São Paulo in recent years, the study also sought to identify entomological and epidemiological aspects that may help gain a better understanding of malaria and improve control of the disease in this region.

\section{Methods}

\section{Study area}

The study was performed in three areas in the Parelheiros subdistrict of São Paulo (Engenheiro Marsilac, Embura and Evangelista de Souza), where there were 64 autochthonous cases of malaria in the last five years. To determine the capture points, the following four subdivisions were defined according to the pattern of human occupation, environmental modifications and notifications of autochthonous malaria (Figure 1):
1) Anthropic zone 1 (Universal Transverse Mercator UTM 23 K 322648/7357521), corresponding to Embura, an urban area with 5,357 inhabitants. This zone, which is the closest to the city, consists of deforested areas with farms, and the main activity is agriculture. In 2007 there were 16 malaria cases, of which only one was symptomatic, and all were treated with the exception of one individual who refused treatment (data from the Embura Health Center).

2) Anthropic zone 2 (UTM 23 K 326439/7355004), corresponding to Engenheiro Marsilac, a small urban center located along the railway line and approximately $5 \mathrm{~km}$ from Embura with a population of about 1,015. From 2006 to 2010, 32 cases were notified but only six of the 32 patients presented with symptoms. All 32 individuals were treated (data from the Marsilac Health Center).

3) Transition zone (UTM 23 K 326931/7353093), corresponding to a rural zone with 461 inhabitants that extends from the periphery of Engenheiro Marsilac, where there are scattered houses, to conserved areas of forest where there is little human influence. Fourteen cases were notified from 2007 to 2010, two of whom presented with symptoms. All individuals were treated (data from the Marsilac Health Center).

4) Sylvatic zone (UTM 23 K 333485/7351745), corresponding to Evangelista de Souza, a continuation of the forested area, where there is little or no human influence. The area is about $6 \mathrm{~km}$ from the transition zone. There are few dwellings and some trails to waterfalls as well as other areas for sporadic ecotourism activities, such as swimming, fishing and hiking. No cases were notified in this zone in the study period.

\section{Entomological collections}

Fourteen monthly captures, one night per month, were made from May 2009 to June 2010 in the anthropic 1 and sylvatic zones (where the collection points were considered fixed), and seven twice-monthly captures in the anthropic 1, anthropic 2 and transition zones (where the collection points were considered mobile) from January 2011 to April 2011. Two methods were used: CDC light traps with $\mathrm{CO}_{2}$ (dry ice) and Shannon traps. The former were installed in open areas, in houses (at floor level) and at the edge of and inside the forest (at ground level and in the canopy at a height of approximately $10 \mathrm{~m}$ ). Collections with these traps lasted twelve hours, beginning in the evening at twilight. Captures with the Shannon traps, which were used with a gas lamp to attract the mosquitoes, were carried out 


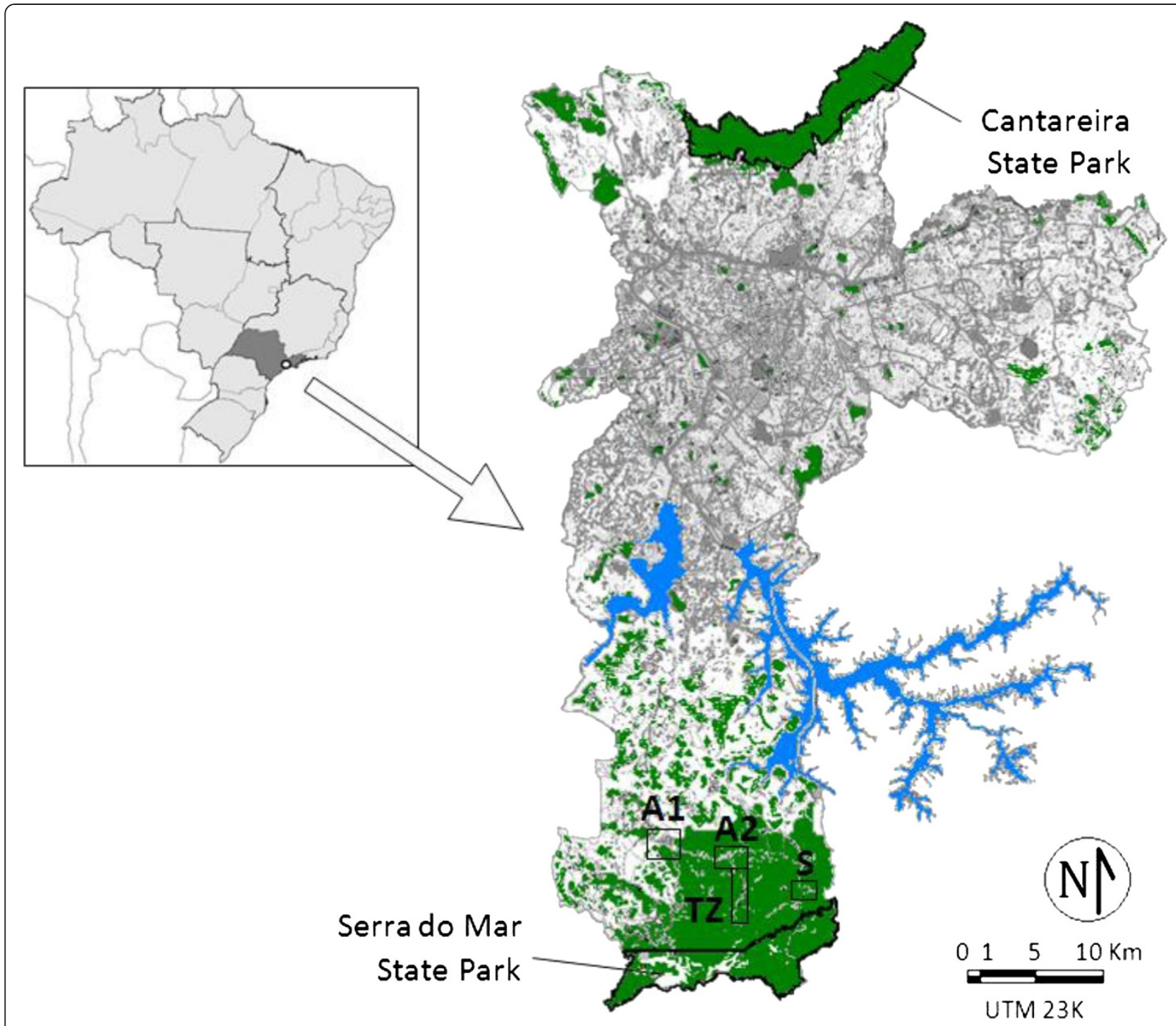

Figure 1 Study area showing the location of the four zones in the Parelheiros subdistrict: A1 (Anthropic 1 Zone), A2 (Anthropic 2 Zone), TZ (Transition Zone) and S (Sylvatic Zone). Major state parks (black line), water storage dams (blue), built-up areas (gray), agricultural and unforested areas (white) and forest environment (green) in the municipality of São Paulo are also shown.

close to the houses and at the edge of the forest for four hours beginning at dusk.

Specimens were kept in silica gel and identified using the key [12] adopted by the Entomology Laboratory at the Public Health Faculty, University of São Paulo. After identification, they were conserved in isopropanol until they were assayed by PCR to detect natural infection. The abbreviations used here for the genera and subgenera of Culicidae follow the revised nomenclature [13].

\section{Polymerase chain reaction (PCR)}

After collection, female anophelines were assayed by PCR to detect Plasmodium infection. DNA was extracted in pools (a maximum of ten specimens/pool) using the Qiagen DNeasy Blood and Tissue kit according to the manufacturer's protocol. The pools were separated by species, day of capture and type of trap. Amplification of the Plasmodium 18S rRNA gene was performed as described by Win et al. [14], who in turn based their protocol on that described by Kimura et al. [15]. The products were electrophoresed in $2 \%$ agarose gel and visualized under ultraviolet light.

\section{Results}

In total, 6,703 female anophelines were collected. $A n$. (Ker.) cruzii predominated and was found in the four zones. Other species were found in smaller numbers (Table 1) and included specimens from genera Nyssorhynchus and Anopheles. Forested areas, i.e., the transition and sylvatic zones, had more An. (Ker.) cruzii 
Table 1 Anopheline females collected in Shannon and CDC traps in four strategic zones in the Parelheiros subdistrict; number of cases of autochthonous malaria between May 2009 and April 2011; and number of pools of Anopheles that were positive for Plasmodium infection by PCR

\begin{tabular}{|c|c|c|c|}
\hline \multirow[t]{2}{*}{ Study area/(Number of malaria cases-year) } & \multirow[t]{2}{*}{ Number of specimens collected } & \multicolumn{2}{|c|}{ PCR results*/month of capture } \\
\hline & & P. vivax & P. malariae \\
\hline \multicolumn{4}{|l|}{ Anthropic 1 Zone (Embura)/(17 - 2007) } \\
\hline An. (Ker.) cruzii & 438 & 2 (Dec 2009; Apr 2011) & $(-)$ \\
\hline An.(Nys.) triannulatus & 29 & 1 (Feb 2011) & 1 (Feb 2011) \\
\hline An. (Nys.) strodei & 34 & $(-)$ & $(-)$ \\
\hline \multicolumn{4}{|l|}{ Anthropic 2 Zone (Marsilac)/(33 - 2006-2009) } \\
\hline An.(Nys.) lutzi & 1 & $1(\operatorname{Jan} 11)$ & $(-)$ \\
\hline An. (Ker.) cruzii & 57 & $(-)$ & $(-)$ \\
\hline An. (Nys.) strodei & 1 & $(-)$ & $(-)$ \\
\hline \multicolumn{4}{|l|}{ Transition Zone/(14 - 2007-2010) } \\
\hline An. (Ker.) cruzii & 1,239 & 1 (Feb 2011) & $(-)$ \\
\hline An. (Nys.) strodei & 47 & $(-)$ & 1 (Feb 2011) \\
\hline \multicolumn{4}{|l|}{ Sylvatic Zone/(0) } \\
\hline An. (Ker.) cruzii & 4,832 & 2 (Jul 2009; Aug 2009) & 1 (Dec 2009) \\
\hline An. (Nys.) strodei & 20 & $(-)$ & $(-)$ \\
\hline An. (Ker.) bellator & 4 & $(-)$ & $(-)$ \\
\hline An. (Ano.) maculipes/pseudomaculipes & 1 & $(-)$ & $(-)$ \\
\hline
\end{tabular}

* Number of pools of Plasmodium-positive Anopheles. Each pool contained from 2 to 10 specimens.

$(-)=$ negative

specimens than those occupied by humans (anthropic zones 1 and 2). Despite their low numbers, Anopheles (Nyssorhynchus) strodei specimens were found in the four zones.

PCR tests to detect Plasmodium were carried out for all females. All DNA samples were negative for $P$. falciparum, seven were positive for $P$. vivax and three for P. malariae.

Three specimens of An. (Ker.) cruzii collected in the sylvatic zone were positive for plasmodia-two for $P$. vivax and one for $P$. malariae - the latter having been collected in a CDC trap in the canopy. In the transition zone, one specimen of $A n$. (Nys.) strodei was positive for P. malariae, and one specimen of An. (Ker.) cruzii was positive for $P$. vivax. It should be noted that forested areas predominate at these collection points (Table 1).

P. vivax was detected in An. (Ker.) cruzii, An. (Nys.) lutzi and An. (Nys.) triannulatus in anthropic zones 1 and 2, which had fewer anophelines and more malaria cases, while $P$. malariae infection was observed in one specimen of An. (Nys.) triannulatus (Table 1).

The capture points, malaria cases and areas where Plasmodium-positive anophelines were found are shown in Figure 2.

\section{Discussion}

In the'90s, the bromeliad-malaria epidemiology associated with the Atlantic Forest was discussed by several authors. Four malaria transmission areas in the state of São Paulo are notable in this context: the northern and southern coasts, the Vale do Ribeira and areas of metropolitan São Paulo surrounded by the Serra do Mar $[1,2,8]$. Serious social and economic problems have arisen in these areas as a result of human occupation and deforestation, which in some areas may be a critical factor in the increase in the number of cases.

Despite control measures implemented in the past to reduce the number of malaria cases, the Parelheiros subdistrict in southern São Paulo has become an important autochthonous focus of malaria and is notable for the number of cases of the disease there in the last five years. Part of the subdistrict is located in CapivariMonos Environmental Preservation Area in the Atlantic Forest (Capivari-Monos APA) in the Serra do Mar, which is considered a target for ecotourism because of the richness of its fauna, flora and history and its proximity to the metropolitan area.

$A n$. (Ker.) cruzii was the predominant species in the study area, and An. (Ker.) bellator, An.(Nys.) lutzi, An. (Nys.) strodei, An.(Nys.) triannulatus and An. (Ano.) maculipes/pseudomaculipes were found in much smaller numbers.

An. (Ker.) cruzii and An. (Ker.) bellator have been incriminated as vectors of human malaria in the Atlantic Forest $[9,10,16]$, and An. (Ker.) cruzii is also a vector of simian malaria in this habitat $[4,17]$. 

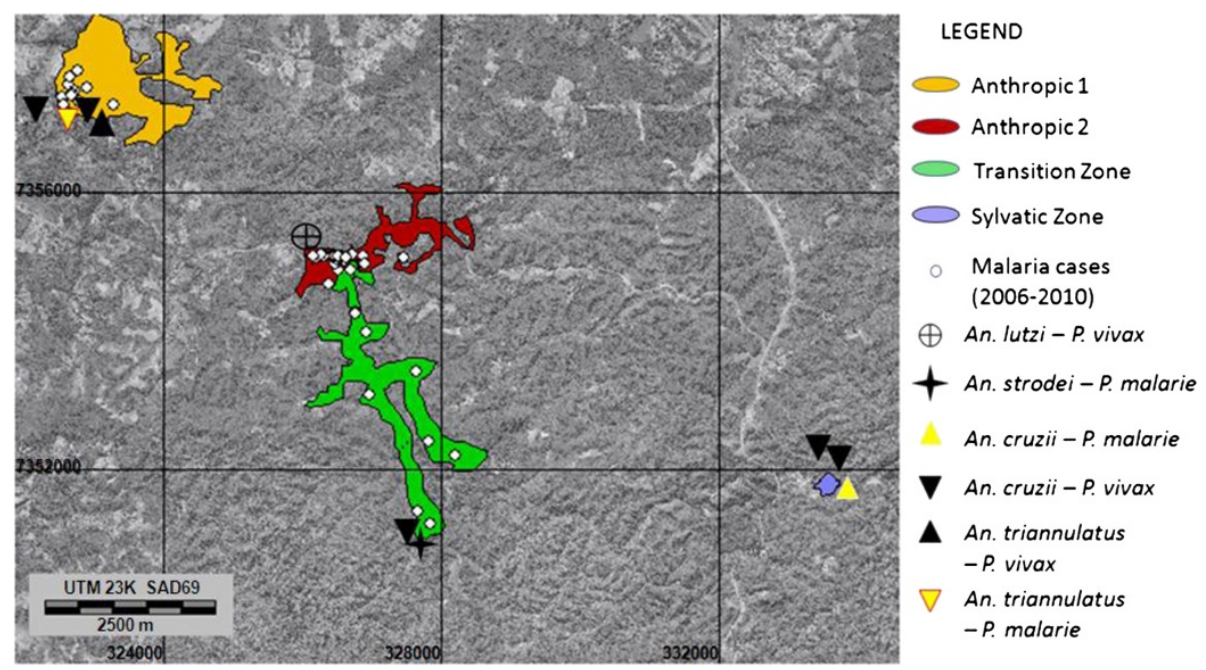

Figure 2 Distribution of autochthonous malaria cases (between 2006 and 2010) and the sites where Plasmodium-positive Anopheles were collected in the four zones in Parelheiros subdistrict. Bright areas indicate urban areas, roads, railroads, agricultural land and pasture; dark gray areas correspond to forest environment. Background: Orthophoto mosaic, scale: 1:5,000; aerial survey of São Paulo Metropolitan Region/EMPLASA (2007).

Subgenus Kerteszia is concentrated in exuberant humid forests, where there is a high density of bromeliads [18]. The density of the species in this subgenus varies according to the extent of human disturbance and deforestation [19]. Reflecting this, the greatest number of $A n$. (Ker.) cruzii was collected in the sylvatic zone. Some of these were naturally infected by $P$. vivax and $P$. malariae.

In the transition zone, where $P$. vivax-infected anophelines were detected, the population lives on ranches or small farms and is therefore in closer contact with mosquitoes. Between 2007 and 2010, Marsilac Health Center notified 14 cases of vivax malaria.

Fewer An. (Ker.) cruzii were collected in the anthropic zones (Embura and Engenheiro Marsilac), where $50 \mathrm{ca}-$ ses were notified from 2006 to 2009 according to the Marsilac Health Center.

As might be expected, these results confirm the importance of $A n$. (Ker.) cruzii as the main vector of malaria in the study region; however, other species were also found to be infected by Plasmodium. An. (Nys.) strodei was positive for $P$. malariae in the transition zone while in the anthropic zones An. (Nys.) triannulatus was positive for $P$. vivax and $P$. malaria and only one specimen of An. (Nys.) lutzi was positive for P. vivax. These findings suggest that other species may play a secondary role in malaria transmission in the Atlantic Forest. Similar results were described in areas surrounded by the Atlantic Forest in the state of Espírito Santo [20].

Although only a few specimens from subgenus Nyssorrhynchus were found, infection by Plasmodium could still be detected, indicating that these anophelines may be important markers of environmental change in areas surrounded by the Atlantic Forest as they are associated with water collections rather than bromeliads. In addition, we found specimens of $A n$. (Nys.) strodei and $A n$. (Nys.) triannulatus engorged with human blood in the anthropic and transition zones (data not shown).

Although there are still rural communities, the study area is under continuous pressure from urban expansion. The constant exposure of the inhabitants to anopheline bites allied to the distribution of housing over a large geographical area leads to the dispersion of asymptomatic human reservoirs [1,2].

However, the hypothesis that malaria may be a zoonotic disease in the Atlantic Forest has been raised in several studies [4-6,21], and the evidence from the present study underlines the importance of further investigation to determine whether monkeys are acting as malaria reservoirs.

Our findings revealed the presence of $P$. malariaepositive $A n$. (Ker.) cruzii in the sylvatic zone and $P$. malariae-positive An. (Nys.) strodei and An. (Nys.) triannulatus in the anthropic zones, suggesting that $P$. malariae circulates in a simian cycle while concomitantly being transmitted by humans.

Although all the individuals in whom malaria was detected were treated and no new cases have been reported, our results indicate that the sources of infection in the study zones have not been eliminated. For example, the last registered cases of malaria in the anthropic 1 zone were in 2007 but P. vivax-positive An. (Ker.) cruzii was detected there in 2011; similarly, the most recently registered case in the transition zone was in 2010, but 
P. vivax-positive An. (Ker.) cruzii and P. malariae-positive $A n$. (Nys) strodei were found there in 2011. These findings indicate that silent transmission is being maintained in asymptomatic cases.

Fewer anophelines were collected in the anthropic zones than in the transition or sylvatic zones. However, infections were detected in anophelines from all four zones. The results for disturbed areas suggest that the risk of contracting malaria in these areas may be greater than in wild areas. As our findings are preliminary and the study is descriptive, further investigation is required to correlate the rate of anopheline infection with the incidence of malaria in the population in the study area.

\section{Conclusion}

Our findings point to situations that are novel to areas of the Atlantic Forest where malaria is endemic and indicate that further research is needed to contribute with discussion of new parameters for malaria surveillance and control in this region.

\section{Competing interests}

The authors declare that they have no competing interests.

\section{Authors' contributions}

All authors were responsible for field collections and the preparation of the manuscript. AMRCD and RSM were responsible for the study design. MBP, AF and AFR were responsible for the identification of mosquitoes. AMRCD and DMP were responsible for the processing of mosquitoes and for analysis. LFM was responsible for the map and for geoprocessing the data. All authors read and approved the final version of the manuscript.

\section{Acknowledgements}

We would like to thank the Health Surveillance Supervision Sector in the São Paulo Municipal Department of Health, the Pedro Matajs Institute and the São Paulo Metropolitan Police, the Marsilac Heath Center (UBS Marsilac) and the Embura Helth Center (UBS Embura).

This project was supported by the Fundação de Amparo à Pesquisa (FAPESP) $\left(n^{\circ} .2008 / 52016-0\right)$ and SUCEN.

\section{Author details}

${ }^{1}$ Biochemistry and Molecular Biology Laboratory, Superintendency for the Control of Endemic Diseases (SUCEN), Rua Paula Souza 166, São Paulo 01027-000, Brazil. 'Epidemiology Department, Faculty of Public Health, University of São Paulo, Av. Dr. Arnaldo715, São Paulo 01246-904, Brazil. ${ }^{3}$ Zoonosis Control Center, Laboratory for the Identification of and Research into Synanthropic Fauna/Lab-Fauna, Rua Santa Eulália 86, São Paulo 02031-020, Brazil. ${ }^{4}$ Culicid Laboratory/SR-03, SUCEN, Pça. Coronel Vitoriano 23, Taubaté 12020-020, Brazil. ${ }^{5}$ Protozoology Laboratory, Institute of Tropical Medicine, University of São Paulo, Av. Dr. Enéas de Carvalho Aguiar 470, São Paulo 05403-000, Brazil. 'Department of Infectious and Parasitic Diseases, Faculty of Medicine, University of São Paulo, Av Dr Arnaldo 455, São Paulo 01246-903, Brazil.

Received: 10 December 2012 Accepted: 27 February 2013 Published: 7 March 2013

\section{References}

1. Curado I, Duarte AM, Lal AA, Oliveira SG, Kloetzel JK: Antibodies anti bloodstream and circumsporozoite antigens (Plasmodium vivax and Plasmodium malariae/P. brasilianum) in areas of very low malaria endemicity in Brazil. Mem Inst Oswaldo Cruz 1997, 92:235-243.

2. Curado I, Malafronte RS, de Castro Duarte AM, Kirchgatter K, Branquinho MS, Bianchi Galati EA: Malaria epidemiology in low-endemicity areas of the
Atlantic Forest in the Vale do Ribeira, São Paulo, Brazil. Acta Trop 2006, 100:54-62.

3. Cerutti C Jr, Boulos M, Coutinho AF, Hatab MCLD, Falqueto A, Rezende HR, Duarte AMRC, Collins W, Malafronte RS, Cerutti C Jr, Boulos M, Coutinho AF, Hatab MCLD, Falqueto A, Rezende HR, Duarte AMRC, Collins W, Malafronte RS: Epidemiologic aspects of the malaria transmission cycle in area of very low incidence in Brazil. Malaria 2007, 6:33.

4. Deane LM: Simian malaria in Brazil. Mem Inst Oswaldo Cruz 1992, 87:1-20.

5. Duarte AM, Porto MA, Curado I, Malafronte RS, Hoffmann EHE, de Oliveira SG, da Silva AM, Kloetzel JK, Gomes AC: Widespread occurrence of antibodies against circumsporozoite protein and against blood forms of Plasmodium vivax, $P$. falciparum and $P$. malariae in brazilian wild monkeys. J Med Primatol 2006, 35:87-96.

6. Duarte AM, Malafronte RS, Cerutti C Jr, Curado I, Paiva BR, Maeda AY, Yamasaki T, Summa ME, Neves DV, Oliveira SG, Gomes AC: Natural Plasmodium infections in Brazilian wild monkeys: reservoirs for human infections? Acta Trop 2008, 107:179-185.

7. Gadelha P: From "Forest malaria" to "bromeliad malária": a case-study of scientific controversy and malaria control. Parassitologia 1994, 36:175-195.

8. Carvalho ME, Glasser CM, Ciaravolo RMC, Etzel A, Santos LA, Ferreira CS: Sorologia da malária vivax no foco de aldeia dos índios, município de Peruíbe, Estado de São Paulo, 1984 a 1986. Cad Saude Publica 1988, 4:276-292.

9. Marrelli MT, Malafronte RS, Sallum MAM, Natal D: Kerteszia subgenus of Anopheles associated with the Brazilian Atlantic rainforest: current knowledge and future challenges. Malaria J 2007, 6:127.

10. Rachou RG: Anofelinos do Brasil: comportamento das espécies vetoras de malária. Rev Bras MalariolDoenças Trop 1958, 10:145-181.

11. Branquinho MS, Marrelli MT, Curado I, Natal D, Barata JM, Tubaki RM, CarreriBruno GC, Menezes RT, Kloetzel JK: Infecção do Anopheles (Kerteszia) cruzii por Plasmodium vivax e Plasmodium vivax variante VK247 nos municípios de São Vicente e Juquitiba, São Paulo. Rev PanamSaludPublica 1997, 2:189-193.

12. Forattini OP: Culicidologia Médica, Edusp, Volume 2. Brazil: São Paulo; 2002.

13. Reinert JF: Revised list of abbreviations for genera and subgenera of Culicidae (Diptera) and notes on generic and subgeneric changes. J Am Mosa Control Assoc 2001, 17:51-55.

14. Win TT, Lin SM, Zhou M, Liu Q, Ferreira MU, Tantular IS, Kojima S, Ishii A, Kawamoto F: Wide distribution of Plasmodium ovale in Myanmar. Trop Med Int Health 2002, 7:231-239.

15. Kimura M, Kaneko O, Liu Q, Kawamoto F, Wataya Y, Otani S, Yamaguchi Y, Tanabe K: Identification of the four species of human parasites by nested PCR that targets variant sequences in the small subunit rRNA gene. Parasitol International 1997, 46:91-95.

16. Consoli RAGB, Lourenço de Oliveira R: Principais mosquitos de importância sanitária no Brasil. Rio de Janeiro: FIOCRUZ; 1994.

17. Deane LM, Ferreira Neto JA, Deane MP, Silveira IPS: Anopheles (Kerteszia) cruzii, a natural vector of the monkey malaria parasites, Plasmodium simium and Plasmodium brasilianum. Trans R Soc Med Hyg 1970, 64:647.

18. Guimarães $A E$, Gentile C, Lopes CM, Sant'Anna A: Ecology of mosquitoes in areas of the national park of "Serra da Bocaina", Brazil II. Monthly frequency and climatic factors. Rev Saude Publica 2001, 35:392-399.

19. Forattini OP, Gomes AC, Natal D, Santos JLF: Observações sobre atividade de mosquitos Culicidae em matas primitivas da planície e perfis epidemiológicos de vários ambientes no Vale do Ribeira, São Paulo, Brasil. Rev Saude Publica 1986, 20:178-203.

20. Rezende HR, Soares RM, Cerutti C Jr, Alves IC, Natal N, Urbinatti PR, Yamasaki T, Falqueto A, Malafronte RS: Entomological characterization and natural infection of anophelines in an área of the Atlantic Forest with autochthonous malaria cases in montainous region of Espírito Santo State, Brazil. Neotrop Entomol 2009, 38:272-280.

21. Yamasaki T, Duarte AM, Curado I, Summa ME, Neves DV, Wunderlich G, Malafronte RS: Detection of etiological agents of malaria in howler monkeys from Atlantic Forests, rescued in regions of São Paulo city, Brazil. J Med Primatol 2011, 40:392-400.

doi:10.1186/1756-3305-6-58

Cite this article as: Duarte et al:: Natural infection in anopheline species and its implications for autochthonous malaria in the Atlantic forest in Brazil. Parasites \& Vectors 2013 6:58. 